\title{
Byssinosis and other respiratory symptoms among factory workers in Akaki textile factory, Ethiopia
}

\author{
Kassahun Alemu ${ }^{1}$, Abera Kumie ${ }^{2}$, Gail Davey²
}

\begin{abstract}
Background: Textile cotton workers are at risk for occupational lung disease, including Byssinosis and chronic Bronchitis. Byssinosis is primarily associated with exposure to cotton dust.

Objectives: To determine the prevalence of and factors associated with byssinosis and respiratory symptoms among workers in cotton mills of Akaki textile factory.

Methods: A cross-sectional study was conducted among 417 randomly selected factory workers. Information was collected through interview using the modified American Thoracic Society standard respiratory symptoms questionnaires. Forced expiratory volume in $1 \mathrm{sec}$ (FEV1), forced vital capacity (FVC) and FEV1/FVC ratio were measured using portable medical spirometers. Area sampling for cotton dust concentration in the work environment was measured using Data RAM 4 real time measurement for 8 hours during a day shift.

Results: The highest prevalence of respiratory symptoms was found in the carding section - cough $77 \%$, phlegm $62 \%$, chest tightness $46 \%$ and dyspnea $62 \%$. The Overall prevalence of chronic bronchitis was $32 \%$. Those working in the carding section appeared 13 times more likely to have chronic bronchitis compared to other sections (Adjusted $\mathrm{OR}=13.4,95 \% \mathrm{CI} 3.43-52.6$ ). The prevalence of byssinosis was $38 \%$; the highest being recorded in the carding section at $84.6 \%$. High exposure to cotton dust was noted among those in the blowing and carding section at mean dust levels of $32.2 \mathrm{mg} / \mathrm{m}^{3}$ and $8 \mathrm{mg} / \mathrm{m}^{3}$, respectively. About $11 \%$ of byssinotics developed severe chronic FEV1 changes.

Conclusion: This study provides evidence of a strong relationship between exposure to cotton dust and byssinosis and other respiratory impairments, which is mediated through chronic ventilator impairments. Preventive measures are warranted in order to reduce the high prevalence of byssinosis and other respiratory disorders in textile manufacturing. [Ethiop. J .Health Dev. 2010;24(2):133-139]
\end{abstract}

\section{Introduction}

Air pollution is a major occupational problem in various industries. Occupational lung disease is recorded in accounts of ancient history (1-3). Industries associated with the processing of cotton, specifically yarn, thread and fabric mills are most associated with worker exposure to cotton dust $(4,5)$. The earliest steps of textile processing release a greater deal of dust in the air, and long-term exposure can leave mill workers with respiratory disorders (6).

Invisible small cotton dust particles enter into the alveoli of the lung through inhalation and accumulate in the lymph causing damage to the alveoli and reducing the capacity of retain oxygen. As the cotton dust accumulates, the worker develops a brown lung and suffers from byssinosis (7).

Byssinosis is a respiratory disease primarily associated with exposure to cotton dust, which is characterized by a feeling of chest tightness that is worst on the first day of the working week and improves as the week progress. Symptoms are usually more pronounced when returning to work after a weekend, holiday or vacation and subside as the worker becomes re-accustomed to the environment (8). Documented prevalences of byssinosis were $8 \%$ in China, $30 \%$ in Indonesia, $37 \%$ in Sudan, and up to $50 \%$ in India (4).
In Bahir Dar, Ethiopia, the prevalence of byssinosis was higher among blowers at $43 \%$ and carders at $37.5 \%$ compared to $4-24 \%$ among workers in other sections (9). Another study in the same place (Y. Abebe, T. Seboxa) revealed even much higher overall prevalence of byssinosis at $45.5 \%$, the highest of which was found in carding $(57.9 \%)$ and in ring frames $(57.1 \%)$ operatives, while the lowest in the weaving preparatory section $(32.1 \%)(10)$.

In general, information is lacking concerning the health effect of cotton dust exposure and its control strategies among textile workers in Ethiopia. This study is intended to explore the dimensions of the byssinosis problem in a textile factory in order to provide useful information for any possible cotton dust control strategies in the country.

\section{Methods}

Study design: A cross-sectional study was undertaken to measure prevalence of byssinosis and other respiratory symptoms among workers in the Akaki textile factory, Addis Ababa. At the time of the study i.e. from March 10/07 to April 30/07, there were 765 production workers in different sections of the factory. Their work involves eight main activities/processes - blowing, carding,

\footnotetext{
${ }^{1}$ University of Gondar, College of Medicine and Health Science, School of Public Health, Environmental Health Department

${ }^{2}$ School of Public Health, Addis Ababa University, Addis Ababa, Ethiopia
} 
drawing, roving, twisting, ring frame, preparatory and weaving.

Sample size and Sampling method: Four hundred eighteen $(55 \%)$ of the production workers (those involved in the direct processing of textile materials, who have been working in the same textile factory for at least one year) were included in the study. The sample size was calculated using the single proportion formula (11), assuming a 95\% confidence level and an anticipated byssinosis prevalence of $45 \%$ (10).

Since the working sections had heterogeneous dust concentrations, the study population was divided into homogenous, mutually exclusive groups/strata. Then, independent samples were selected from each working section according to their sizes as ascertained from rosters.

\section{Data collection procedures}

Questionnaires: The questionnaire was modified from the American Thoracic Society (ATS) questionnaire (12), translated from English to Amharic, and then translated back to English by a different translator to verify accuracy. It was pre-tested and found to be applicable for the study population. It was administered via a oneon-one interview by trained university graduates. The questions included personal and work characteristics, use of personal protective devices, respiratory health symptoms (such as symptoms of dyspnea, cough, phlegm chest tightness, and chronic bronchitis), smoking habits and detailed occupational history, previous history of asthma, among others.

Ventilatory lung function test: Pulmonary function test were conducted by trained nurses. Forced expiratory spirograms were performed before work shifts on the first day back to work after two days' rest using a handheld portable spirometer (MicroMedical, UK). The instrument was calibrated as per the instruction manual. Workers were asked to refrain from smoking for at least 1 hour before performing the test and directed to a test room isolated from the work area. Each worker was told to breathe into a mouthpiece connected to an instrument and instructed to breathe in fully form a normal breathing pattern and then blow into the apparatus, without interruption, as hard, fast, and completely as possible. For each participant, forced vital capacity (FVC), forced expiratory volume in $1 \mathrm{sec}$ (FEV1), and forced expiratory volume in $1 \mathrm{sec}$ to forced vital capacity ratio (FEV1/FVC) were measured. The average of the three best results was taken. The predicted values were used to determine whether the study participants measured values were normal( test results was compared with tables of normal values that use variables such as age, gender, body size and race as a method of standardization) or not. The values measured were adjusted for each individual's height, age, and gender (13).
Environmental Measurements: An area sampler was used to measure dust concentrations in the work environment using the MIE Data RAM 4 (Data-logging Real Time Aerosol Monitor 4, USA), which is designed to measure the concentration of airborne particulate matter. The configuration has been optimized for the measurement of the fine particle fraction of airborne dust. It was placed and operated centrally about 1.5 meters above the floor of the breathing zone within the area to be monitored, away from localized air currents due to fans, blowers, ventilation intakes, or exhausts (14). A total of six dust samples were collected in the mill house over the 8-h day work shift. The instrument was calibrated as per the instruction manual.

Data Analysis: EPI-Info version 6.04d was used for data entry, cleaning and validation. Data analysis was performed using SPSS version 13.0. About $10 \%$ of the questionnaires were double entered to verify accuracy of data entry, and no discrepancies were noted. Prevalence and adjusted odds ratio (OR) were calculated for each respiratory symptom and for byssinosis. Univariate analysis was used to test the significance of relationships between variables, and multivariate logistic regression analysis, to examine independent predicative factors for individual symptoms and byssinosis. One way ANOVA was used to compare the means of pulmonary lung function tests of the observed value of FEV1 and FVC and the predicted FEV1 and FVC.

\section{Grading Byssinosis:}

Byssinosis: was defined by Schilling's grading (4).

Grade 0: no symptoms of chest tightness or breathlessness on Monday

Grade 1/2: occasional chest tightness or breathing difficulty on the first day of the working week

Grade 1: chest tightness and/or breathlessness on Monday only.

Grade 2: chest tightness and/or breathlessness on Monday and other weekdays

Grade 3: grade 2 symptoms accompanied by evidence of permanent impairment in capacity from reduced ventilator defect

\section{Results}

Socio-demographic characteristics: Most study participants were males $(54.2 \%)$. Their mean age was 46.7 years and about $39 \%$ were 50 years or older. The majority $(80 \%)$ were married. Half of them cannot read or write (Table 1).

The mean duration of work in the cotton mill house was about 26 years. Most of the participants (92.6\%) did not use protective devices at work. Smoking is not common among the study participants with only $2.6 \%$ were currently smoking while $5.7 \%$ were ex-smokers. 
Table1: Background characteristics of study participants, Akaki textile factory, Addis Ababa, Ethiopia 2007 ( $n=417$ )

\begin{tabular}{|c|c|c|}
\hline $\begin{array}{l}\text { Socio-demographic } \\
\text { characteristics }\end{array}$ & $\begin{array}{l}\text { No of } \\
\text { participants }\end{array}$ & Percent \\
\hline \multicolumn{3}{|l|}{ Sex } \\
\hline Male & 226 & 54.2 \\
\hline Female & 191 & 45.8 \\
\hline \multicolumn{3}{|l|}{ Age in years } \\
\hline$<40$ & 110 & 26.5 \\
\hline $40-49$ & 141 & 33.0 \\
\hline$\geq 50$ & 161 & 38.8 \\
\hline \multicolumn{3}{|l|}{ Marital Status } \\
\hline Single & 15 & 3.6 \\
\hline Married & 335 & 80 \\
\hline Divorced & 35 & 8.4 \\
\hline Widowed & 32 & 7.7 \\
\hline \multicolumn{3}{|l|}{ Educational status } \\
\hline Cannot read/wrote & 74 & 17.7 \\
\hline Literate & 206 & 49.4 \\
\hline Primary & 102 & 24.5 \\
\hline Junior high school & 32 & 7.7 \\
\hline Hiah school complete & 3 & 0.7 \\
\hline \multicolumn{3}{|l|}{ Religion } \\
\hline Orthodox & 379 & 90.9 \\
\hline Muslim & 24 & 5.8 \\
\hline Protestant & 10 & 2.4 \\
\hline Catholic & 1 & 0.2 \\
\hline Others & 3 & 0.7 \\
\hline \multicolumn{3}{|l|}{ Exposure status in years } \\
\hline$<20$ & 124 & 29.7 \\
\hline $20-20$ & 150 & 359 \\
\hline$>30$ & 143 & 34. \\
\hline
\end{tabular}

Prevalence of respiratory symptoms: The overall prevalence of respiratory symptoms in the study participants were - cough (21\%), phlegm (18\%), chest tightness $(15.0 \%)$ and dyspnea (38.1\%).The highest proportions of respiratory symptoms (cough 77\%, phlegm $62 \%$, chest tightness $46 \%$, and dyspnea $62 \%$ ) were found in the carding section. After controlling for sex, age, smoking, occupational history and using protective devices, workers in the carding sections were nearly 13 times and 8 times as likely to report phlegm and chest tightness, respectively, compared to those in the weaving section. Workers in the blowing section were 7 times more likely to have dyspnea than those in other sections (Table 2).

Prevalence of Byssinosis: The overall prevalence of byssinosis in the study population was $38.0 \%$. It was higher among workers in the spinning department $(61.2 \%)$ than those in the weaving (15.7\%). This pattern holds for each grade of byssinosis.

Table 2: Respiratory symptoms and working sections of study participants, Akaki textile factory, Addis Ababa, Ethiopia, 2007 $(n=417)$

\begin{tabular}{|c|c|c|c|c|}
\hline Section & Resp & ymptoms & Crude OR ( 95\% CI) & Adjusted OR (95\% CI) \\
\hline Cough & Yes & No & & \\
\hline Blowing & 5 & 16 & $0.53(0.15,1.95)$ & $0.5(0.04,4.6)$ \\
\hline Roving & 21 & 67 & $1.90(0.85,22.1)$ & $4.8(0.59,39.2)$ \\
\hline Ring frame & 14 & 26 & $3.27(1.27,8.5)$ & $3.1(0.42,22.7)$ \\
\hline Preparatory & 17 & 97 & $1.1(0.46,2.40)$ & $1.1(0.14,9.2)$ \\
\hline Weaving & 14 & 85 & 1.00 & 1.00 \\
\hline Phlegm & Yes & No & & \\
\hline Blowing & 6 & 15 & $3.2(0.89,11.35)$ & $3.5(1.02,11.9)$ \\
\hline Carding & 8 & 5 & $12.8(3.06,56.46)$ & $12.9\left(3.32,50^{*}\right)$ \\
\hline Drawing & 4 & 14 & $2.29(0.53,9.39)$ & $2.3(0.58,8.7)$ \\
\hline Roving & 18 & 70 & $2.06(0.85,5.02)$ & $2.7\left(1.1,6.7^{*}\right)$ \\
\hline Reeling & 2 & 20 & $0.8(0.11,4.32)$ & $1.3(0.23,7.3)$ \\
\hline Ring frame & 12 & 28 & $3.43(1.24,9.51)$ & $4.4\left(1.53,12.8^{*}\right)$ \\
\hline Preparatory & 14 & 100 & $1.12(0.45,2.81)$ & $1.5(0.55,5.3)$ \\
\hline Weaving & 11 & 88 & 1.00 & 1.00 \\
\hline Chest tightness & Yes & No & & \\
\hline Blowing & 3 & 18 & $1.89(0.36,9.04)$ & $1.6(0.35,7.1)$ \\
\hline Carding & 6 & 7 & $9.75(2.22,44.19)$ & $7.8\left(1.97,30.8^{*}\right)$ \\
\hline Drawing & 5 & 13 & $4.38(1.05,18.08)$ & $3.8\left(1.02,14.4^{*}\right)$ \\
\hline Roving & 22 & 66 & $3.74(1.49,9.49)$ & $3.3\left(1.26,8.6^{*}\right)$ \\
\hline Reeling & 5 & 17 & $3.5(0.83,13.26)$ & $2.9(0.65,12.5)$ \\
\hline Ring frame & 6 & 34 & $2.01(0.57,7.01)$ & $10.9(0.58,2.03)$ \\
\hline Preparatory & 7 & 107 & $0.74(0.23,2.37)$ & $2.1(0.21,2.5)$ \\
\hline Weaving & 8 & 91 & 1.00 & 1.00 \\
\hline Dyspnea & Yes & No & & \\
\hline Blowing & 4 & 17 & $1.13(0.28,4.74)$ & $6.9\left(1.91,25.7^{*}\right)$ \\
\hline Carding & 8 & 5 & $2.27(0.75,6.77)$ & $2.3(0.76,7.1)$ \\
\hline Drawing & 8 & 10 & $7.72(1.96,31.68)$ & $2.5\left(1.19,5.3^{*}\right)$ \\
\hline Roving & 38 & 50 & $18.33(7.11,48.60)$ & $1.8(0.56,5.9)^{\prime}$ \\
\hline Reeling & 8 & 14 & $0.77(0.28,2.07)$ & $0.01\left(0.00,2.2^{*}\right)$ \\
\hline Ring frame & 22 & 18 & $5.90(2.43,14.48)$ & $3.64(1.45,9.1)$ \\
\hline Preparatory & 54 & 60 & $4.34(2.19,8.67)$ & $2.2(0.95,4.9)$ \\
\hline Weaving & 17 & 82 & 1.00 & 1.00 \\
\hline
\end{tabular}

* Significance at $\mathrm{P}<0.05$ 
High prevalence of byssinosis was documented in the carding $(84.6 \%)$, drawing $(72.2 \%)$ and ring frame $(63.0 \%)$ sections. The highest prevalence of grade I byssinosis was found in the twisting (50\%), carding (46.2\%) and drawing (44.4\%) sections. Likewise, highprevalence of grade II byssinosis was found in the carding section (15.4\%). After controlling for age, sex, smoking status, occupational history and use of protective devices of factory workers, those who had worked in the twisting, ring frame, carding and drawing sections were 21 times, 16 times, 12 times and 12 times, respectively, more likely to have grade I byssinosis than those in weaving section.
Those in the carding section were 27 times more likely to have grade $1 / 2$ byssinosis (Table 3 ).

Of those who had byssinosis, $36.8 \%$ were non-smokers, while eight of eleven smokers had byssinosis. No significant difference was found in the prevalence of byssinosis between smokers and non-smokers. Although the prevalence of byssinosis appeared to increase with age, the difference was not statistically significant (Table 4). There was no significant association between years of exposure and grade of byssinosis.

\begin{tabular}{|c|c|c|c|c|}
\hline Section & \multicolumn{2}{|c|}{ Grade of byssinosis } & \multirow[t]{2}{*}{ Crude OR ( $95 \%$ CI) } & \multirow[t]{2}{*}{ Adjusted OR (95\% CI) } \\
\hline Grade $1 / 2$ & Yes & No & & \\
\hline Blowing & 2 & 19 & $5.1(0.4,55.2)$ & $12.8^{* *}(1.21,135.8)$ \\
\hline Carding & 3 & 10 & $14.5(1.7,145.00)$ & $27.3^{* * *}(2.81,265.7)$ \\
\hline Drawing & 2 & 16 & $6.0(0.56,66.51)$ & $0.1(0.00,3.9)$ \\
\hline Roving & 4 & 36 & $5.3(0.80,44.56)$ & $11.8^{* *}(1.68,83.4)$ \\
\hline Twisting & 3 & 19 & $7.6(0.95,71.4)$ & $24.7^{* *}(1.87,327.8)$ \\
\hline Ring frame & 2 & 38 & $2.5(0.25,26.55)$ & $0.0(0.000,2.7)$ \\
\hline Preparatory & 2 & 112 & $0.8(0.09,8.79)$ & $8.3(0.000,2.7)^{\prime}$ \\
\hline Weaving & 2 & 97 & 1.00 & 1.00 \\
\hline Grade I & Yes & No & & \\
\hline Blowing & 5 & 16 & $1.4(0.39,4.84)$ & $4.8^{* * *}(1.25,18.8)$ \\
\hline Carding & 6 & 7 & $3.8(1.00,14.95)$ & $12.3^{* * *}(3.0,50.4)$ \\
\hline Drawing & 8 & 10 & $3.6(1.10,11.77)$ & $12.4^{\star \star *}(3.3,45.7)$ \\
\hline Roving & 32 & 8 & $18.0(6.56,51.19)$ & $9.6^{\star * *}(3.48,26.3)$ \\
\hline Twisting & 10 & 12 & $3.7(1.26,11.20)$ & $21.6^{\star * *}(5.56,83.6)$ \\
\hline Ring frame & 18 & 22 & $3.6(1.53,8.93)$ & $16.2^{* * *}(5.20,50.5)$ \\
\hline Preparatory & 7 & 107 & $0.2(0.11,0.79)$ & $3.5^{* *}(1.2,10.8)$ \\
\hline Weaving & 18 & 81 & 1.00 & 1.00 \\
\hline Grade II & Yes & No & & \\
\hline Blowing & 2 & 19 & $2.5(0.29,17.73)$ & $1.9(0.29,13.1)$ \\
\hline Carding & 2 & 11 & $4.3(0.48,33.02)$ & $3.3(0.01,21.9)$ \\
\hline Drawing & 3 & 15 & $4.7(0.75,29.04)$ & $3.8(0.71,21.1)$ \\
\hline Roving & 10 & 30 & $7.9(2.07,37.68)$ & $2.0(0.55,7.7)$ \\
\hline Twisting & 1 & 21 & $1.1(0.13,9.58)$ & $0.7(0.07,8.6)$ \\
\hline Ring frame & 5 & 35 & $3.3(0.73,16.18)$ & $2.4(0.53,11.3)$ \\
\hline Preparatory & 4 & 110 & $0.8(0.18,4.24)$ & $0.5(0.11,3.1)$ \\
\hline Weaving & 4 & 95 & 1.00 & 1.00 \\
\hline
\end{tabular}

* Model adjusted for sex, age, smoking status, occupational history and work exposure

** Significant at $P<0.05,{ }^{* * *}$ significant at $P<0.001$

Table 4: Prevalence of byssinosis by ages, Akaki textile factory, Addis Ababa, Ethiopia 2007 ( $N=417$ ).

\begin{tabular}{|c|c|c|c|c|}
\hline Section & \multicolumn{2}{|c|}{ Grade of byssinosis } & Crude OR ( $95 \%$ CI) & Adjusted OR (95\% CI) \\
\hline Grade $1 / 2$ & Yes & No & & \\
\hline$<40$ & 2 & 108 & 1.00 & \\
\hline $40-49$ & 8 & 132 & $3.2(0.63,28.81)$ & $(0.03,1.75)$ \\
\hline$\geq 50$ & 10 & 155 & $3.4(0.70,23.51)$ & $(0.02,1.53)$ \\
\hline Grade I & Yes & No & & \\
\hline$<40$ & 20 & 90 & 1.00 & \\
\hline $40-49$ & 38 & 104 & $1.6(0.86,3.17)$ & $(0.64,3.41)$ \\
\hline$\geq 50$ & 48 & 117 & $1.8(0.99,3.48)$ & $(0.55,3.63)$ \\
\hline Grade II & Yes & No & & \\
\hline$<40$ & 5 & 105 & 1.00 & \\
\hline $40-49$ & 11 & 131 & $1.7(0.54,6.03)$ & $(0.48,8.56)$ \\
\hline$\geq 50$ & 15 & 150 & $2.1(0.69,6.84)$ & $(0.5,11.1)$ \\
\hline
\end{tabular}

* Model adjusted for sex, age, working sections, occupational history and work exposure. 
Table 5: Prevalence of chronic bronchitis according to selected factors, Akaki textile factory, Addis Ababa, Ethiopia $2007(n=417)$

\begin{tabular}{|c|c|c|c|c|}
\hline \multirow[t]{2}{*}{ Factors } & \multicolumn{2}{|c|}{ Chronic bronchitis } & \multirow[t]{2}{*}{ Crude OR ( 95\% CI) } & \multirow[t]{2}{*}{ Adjusted OR (95\% CI) } \\
\hline & Yes & No & & \\
\hline \multicolumn{5}{|l|}{ Sections } \\
\hline Blowing & 3 & 18 & $0.8(0.18,3.65)$ & $0.9(0.2,3.8)$ \\
\hline Carding & 9 & 4 & $11.6(2.80,52.37)$ & $13.4\left(3.4,52.6^{*}\right)$ \\
\hline Drawing & 6 & 12 & $2.5(0.74,8.97)$ & $2.7(0.8,8.8)$ \\
\hline Roving & 23 & 65 & $1.8(0.85,3.99)$ & $2.3(1.0,5.2)$ \\
\hline Reeling & 4 & 18 & $1.1(0.29,4.31)$ & $1.2(0.8,9.8)$ \\
\hline Ring frame & 14 & 26 & $2.7(1.11,7.04)$ & $1.5(0.6,3.8)$ \\
\hline Preparatory & 21 & 93 & $1.1(0.54,2.54)$ & 1.00 \\
\hline Weaving sec. & 16 & 83 & 1.00 & \\
\hline \multicolumn{5}{|l|}{ Exposure } \\
\hline$<20$ years & 19 & 97 & 1.00 & 1.00 \\
\hline 20-29years & 45 & 113 & $2.0(1.07,3.80)$ & $2.5\left(1.1,5.6^{*}\right)$ \\
\hline$>30$ years & 32 & 111 & $1.4(0.75,2.90)$ & $1.5(0.6,3.9)$ \\
\hline \multicolumn{5}{|l|}{ Age in years } \\
\hline$<40$ & 18 & 93 & 1.00 & 1.00 \\
\hline $40-49$ & 39 & 102 & $1.9(1.00,3.84)$ & $1.2(0.3,2.2)$ \\
\hline$>50$ & 49 & 125 & $1.5(0.82,3.11)$ & $0.9(0.3,2.2)$ \\
\hline \multicolumn{5}{|l|}{ Smoke } \\
\hline Non-smokers & 92 & 312 & 1.00 & 1.00 \\
\hline Smokers & 4 & 7 & $1.9(0.47,7.57)$ & $2.1(0.6,7.6)$ \\
\hline
\end{tabular}

* Significant at $p<0.05$

Prevalence of chronic bronchitis: The prevalence of chronic bronchitis was highest in the carding section $(69.2 \%)$ and lowest in the weaving section $(16.2 \%)$. After adjusting for sex, age, smoking status, occupational history and use of protective devices, workers in the carding sections were 13 times more likely to have chronic bronchitis than those in the waving section. The prevalence of chronic bronchitis was higher in the spinning department than the weaving department (29.4\%vs. $17.0 \%)$ (Table 5$)$.
Distribution of cotton dusts in the work area: Workers in all working areas were exposed to the highest level of cotton dust with overall mean dust level of $(14,02$ $\mathrm{mg} / \mathrm{m}^{3}$ ). The highest was in blowing section $\left(32.2 \mathrm{mg} / \mathrm{m}^{3}\right)$ and the lowest was in weaving section $\left(2.0 \mathrm{mg} / \mathrm{m}^{3}\right)$. Cotton dust particle over all diameter was $4 \mu \mathrm{m}$ aerodynamic with the highest (blowing section; $4.07 \mu \mathrm{m}$ ) and lowest (carding section, $0.9 \mu \mathrm{m}$ ). The concentrations of cotton dust in working sections were not normally distributed (skewed to positive direction). This means that it has a long tail in the positive direction (Table6).

Table 6: Cotton dust concentrations in working sections of Akaki textile factory, Addis Ababa, Ethiopia, 2007

\begin{tabular}{llllll}
\hline \multirow{2}{*}{ Sections } & \multicolumn{2}{c}{ Mass in $\mathbf{~} \mathbf{g} / \mathbf{m}^{3}$} & \multirow{2}{*}{ Median } & & \multicolumn{2}{c}{ Diameter in $\boldsymbol{\mu m}$} \\
\cline { 2 - 3 } & Maximum & Mean & & Maximum & Mean \\
\hline Blowing & 61.44 & 32.20 & 34.78 & 4.10 & 4.07 \\
Carding & 21.03 & 8.00 & 8.88 & 4.13 & .90 \\
Drawing & 7.43 & 5.62 & 5.99 & 4.13 & 3.96 \\
Ring frame & 4.81 & 3.30 & 3.24 & 4.13 & 3.99 \\
Preparatory & 2.42 & 2.00 & 1.75 & 4.13 & 3.91 \\
Weaving & 3.20 & 2.00 & 1.50 & 4.13 & 3.98 \\
All combined (overall) & & 14.02 & & & 3.96 \\
\hline
\end{tabular}

Lung function measurements: According to the World Health Organization (WHO) classifications of Lung diseases, $11 \%$ of the study participants had severe lung impairment. Of the byssinotic workers $32 \%$ to $45 \%$ showed slight to moderate chronic impairment and $52.0 \%$ to $54.8 \%$ had no chronic impairment (Table 7).

\section{Discussion}

The relationships between type of occupation and pulmonary contaminants and respiratory symptoms have been studied since the late 1970s (15). In this study, the authors studied the prevalence of byssinosis and other respiratory symptoms among textile cotton mill house production workers in Akaki, Addis Ababa. In this study, the prevalence of respiratory symptoms were high in the spinning department, and workers in the spinning department were more likely than others to have cough, phlegm, chest tightness and dyspnea. Respiratory-related illness symptoms were highly prevalent among the workers in the blow/card rooms(15) and about twice as many workers in the spinning department had respiratory symptoms as in the weaving department (16). 
Table 7: Chronic changes in FEV 1 by years of exposure in among production workers in Akaki textile factory Addis Ababa, Ethiopia 2006/2007

\begin{tabular}{lllll}
\hline \multirow{2}{*}{$\begin{array}{l}\text { Grade of Byssinosis } \\
\text { No. of participants }\end{array}$} & \multicolumn{3}{l}{ Chronic FEV 1 changes } \\
\cline { 2 - 5 } & & $\begin{array}{l}\text { Normal } \mathbf{( > 8 0 \%} \\
\text { pred. FEV1 }\end{array}$ & $\begin{array}{l}\text { of } \\
\text { of pred. FEV 1) }\end{array}$ & $\begin{array}{l}\text { Severe }(<60 \% \text { pred. } \\
\text { FEV 1) }\end{array}$ \\
\hline Grade $1 / 2$ & 11 & $6(54.5 \%)$ & $5(45.5 \%)$ & - \\
Grade I & 62 & $34(54.8 \%)$ & $20(32.3 \%)$ & $8(12.9 \%)$ \\
Grade II & 19 & $10(52.6 \%)$ & $7(36.8 \%)$ & $2(10.5 \%)$ \\
Total & 212 & $50(25.3 \%)$ & $32(34.8 \%)$ & $10(10.0 \%)$ \\
\hline
\end{tabular}

The highest prevalence of respiratory symptoms (phlegm $62 \%$, chest tightness $46 \%$ and dyspnea $62 \%$ ) were found in the carding section comparing with other sections, and workers in these sections were 13 times and 8 times more likely to contract phlegm and tightness, respectively. Workers in blowing sections were seven times more likely to have dyspnea than the other sections. This study showed higher prevalence of respiratory symptoms than in other textile studies, for example those in China (frequent cough $2.23 \%$, frequent phlegm $3.24 \%$, shortness of breath $4.54 \%$ (17), Bangladesh (4.3\%) chest tightness or breathlessness (16). The study done by Mehdi in South Tehran, Iran, studied in industries, found a significantly higher prevalence of respiratory symptoms among textile industrial workers (cough 30.8\%, phlegm $53.8 \%$ and dyspnea $65 \%$ ) and the risk of respiratory disorders was also raised (1).

Schilling and his colleagues undertook the first epidemiologic studies on byssinosis in the 1950s. It is known that the prevalence of byssinosis is decreasing in industrialized countries while it remains at high levels in developing countries $(5,15)$. The overall prevalence of byssinosis among cotton mill workers in this study was $38.0 \%$, which was lower than in the studies conducted in Bahir Dar by Woldyohanis et al $(43 \%)(9)$ and Abebe et al (45\%) (10), or in Khartoum, Sudan (46\%) (13).

This investigation showed higher prevalence of byssinosis in the carding (84.6\%), drawing (72.2\%) and ring frame $(63.0 \%)$ sections compared to the study conducted in Bahir Dar (carding 57.9\%, and ring frame $57.1 \%)$, or in Khartoum (67\% among blowers, $40 \%$ in carders and draw-frame workers, $(9,10,13)$. The high prevalence of byssinosis in these sections may be because the sections were not segregated from the card room, or because of older style machines. The lowest prevalence of byssinosis in this study was in the preparatory $(11.4 \%)$ and weaving $(24.0 \%)$ sections. However, in Lancashire textile weavers, the prevalence of byssinosis was $0.3 \%$ which is 38 to 84 times lower than this investigation (15).

Chest tightness and breathing difficulty on Monday (grade I byssinosis) were more common in the reeling $(50 \%)$, carding $(46.2 \%)$ and drawing (44.4\%) sections. Similarly, chest tightness or breathing difficulty on Monday and other days (grade II byssinosis) were higher in the carding section (15.4\%). Production workers worked in reeling, ring frame, carding and drawing sections were 21 times, 16 times, 12 times and 12 times more likely to have grade I byssinosis than the other sections, respectively $(\mathrm{p}<0.001)$. Others have suggested that prevalence of byssinosis is common particularly among those exposed to high concentration of dusts for a longer time than other factors (18).

This study revealed that of those who had byssinosis (147/157) 94.9\% were non-smokers, while eight smokers of eleven had byssinosis. No significance difference was observed in the prevalence of byssinosis between smokers and non-smokers, but this may be because the numbers of smokers were small in this study. In Taiwan, smoking potentiated the effect of cotton dust exposure on respiratory symptoms and byssinosis. Moreover, and the prevalence of impaired lung function in smokers was significantly higher than in non-smokers (19).

There was a non-significant increase in prevalence of byssinosis with age. Other studies have found that severity of byssinosis increases with duration of exposure which was a population-based cohort of adults aged 4574 years and different from on the study design and age categories $(2,14)$.

Workers in all working sections were exposed to the high level of cotton dust less than $4 \mu \mathrm{m}$ diameter (blowing $32.2 \mathrm{mg} / \mathrm{m} 3$, carding $8.0 \mathrm{mg} / \mathrm{m} 3$, drawing $5.62 \mathrm{mg} / \mathrm{m} 3$, ring frame $3.3 \mathrm{mg} / \mathrm{m} 3$, preparatory $2.0 \mathrm{mg} / \mathrm{m} 3$ and weaving $2.0 \mathrm{mg} / \mathrm{m} 3$ ). These levels are 4 to 64 times above the permissible threshold limit value (TLV, 0.5 $\mathrm{mg} / \mathrm{m}^{3}$ ) in the health and safety guidelines used in the United Kingdom (20). The Committee of Hygiene Standards of the British Occupational Hygiene Society enforced the standard and concluded that the prevalence of byssinosis could be reduced to less than $4 \%$ if cotton dust exposure was reduced to less than $0.5 \mathrm{mg} / \mathrm{m}^{3}$, as measured by the work area sampling technique (21). In the United States, cotton dust standard levels are 0.2 $\mathrm{mg} / \mathrm{m}^{3}$ for the areas of packing, carding and spinning, and $0.75 \mathrm{mg} / \mathrm{m}^{3}$ for the slashing and weaving areas (22).

Particularly the mean of twisting, carding, preparatory, roving and drawing sections were slower than the other sections. The study done in Bahir Dar Textile reported

\footnotetext{
${ }^{1}$ University of Gondar, College of Medicine and Health Science, School of Public Health, Environmental Health Department

${ }^{2}$ School of Public Health, Addis Ababa University, Addis Ababa, Ethiopia
} 
that the mean measured values of ventilatory capacity (FEV1 and FVC) were significantly reduced in the exposed groups compared with controls $(\mathrm{P}<0.01)(9)$.

More importantly, $11 \%$ had severe impairment. Of the byssinotic workers, $32 \%$ to $45 \%$ showed slight to moderate chronic impairment and $52.0 \%$ to $54.8 \%$ had no chronic impairment. The small sample size was the limitation which affected the confidence interval.

\section{Conclusion}

The prevalence of byssinosis and other respiratory symptoms were high. The concentrations of cotton dust in all sections were found to be above the permissible limits value (TLV). All in all, preventive measures are of supreme importance in minimizing the prevalence of byssinosis and other respiratory disorders using appropriate protective device, work rotation, and controlling dust.

\section{Acknowledgments}

We would like to acknowledge Addis Ababa University, school of Public Health, Medical faculty for provision of fund for undertaking this work. Our appreciations extend to labor and social affairs bureau and Black Lion specialized hospital chest unit for giving instruments for measuring concentration of cotton dust and lung function test. Furthermore, Akaki textile administrators and production workers are duly acknowledged to their willingness.

\section{References}

1. Mehdi G, Masaharu K, Mansour R, Ali R, Adel M, Hamid R. Prevalence of Respiratory Symptoms among Workers in Industries of South Tehran, Iran. Industrial Health 2006;44:218-224.

2. Tricia D, Woon-Puay K, Hin-Peng L, David K, Mimi C, and Stephanie J. Vapor, Dust, and Smoke Exposure in Relation to Adult-Onset Asthma and Chronic Respiratory Symptoms, The Singapore Chinese Health Study American Journal of Epidemiology 2006;163(12):1118-1128.

3. Barry S, David H. Occupational health recognizing and preventing work-related disease. Little Brown and company. Boston/New York/Toronto/London/. Third edition, 2001.

4. Neil E, Chter S. Respiratory effect and other disease patterns in textile industry. Available from: URL: $\quad$ http://www. ilo.org/encyclopedia/? doc\&nd $=857200488 \& n h=0$.

5. Michael D. Respiratory Diseases and Their Prevention: A Look at Industrial Dust and Its Control facility safety management May 2004.

6. Focus-march, 21, occupational health: Cotton Mill Dust May Be Carrier as Well as Culprit in Respiratory Illness, 2003.

7. Yih-Ming S, Jenn-Rong S, Jia-Yih S, Ching-Hui L, Saou-Hsing L . Additive Effect of Smoking and Cotton Dust Exposure on Respiratory Symptoms and Pulmonary Function of Cotton Textile Workers. Industrial health,2003;41:109-115.
8. Wang X, Eijen E, Zhang H, Sun B, Dai H, Pan L, .Respiratory symptoms and cotton dust exposure: results of 15 year follow up observation, Occup and Environ Med 2003;60:935-41.

9. Wolde Yohannis M, Bergevin Y, Mgeni A, Theriault G. Respiratory problems among textile mill workers in Bahir Dar, Ethiopia. Br J Ind Med 1991;48:110-5.

10. Abebe Y, Seboxa T. Byssinosis and other respiratory disorders among textile mill workers in Bahir Dar North West Ethiopia. Ethiop Med J 1995;13(1):3339.

11. Wayne W. Daniel. Biostatistics: foundation for analysis in the health Science.7th edition. John Wily and sons INC, New York, 1999.

12. American lung association occupational lung disease. An introduction, 1983 [cited 2004 Oct]; Available from: URL: http//www.lungusa.org) (accessed Oct, 2004).

13. Awaad E., Osman Y, Haimmi Y. Byssinosis: environmental and respiratory symptoms among textile workers in Sudan. Int Arch Occup Environ Health 1986;57:101-8.

14. Health and Safety Executive. Guidance note EH25, cotton dust sampling. London:HMSO,1980

15. Raza S, Fletcher A, Pickering C, Niven R, Faragher E. Ventilatory function and personal breathing zone dust concentrations in Lancashire textile weavers. Occupational and Environmental Medicine 1999;56:520-526.

16. David C, Xiao-Rong W. Longitudinal Changes in pulmonary function and Respiratory Symptoms in Cotton Textile Workers a 15-yr Follow-up Study. Am. J. Respir. Crit. Care Med., 2001;63(4):847-853.

17. Liou S .Occupational disease profile in Taiwan, Republic of China, Industrial Health 1994;32:107-18.

18. Ahasan M, Ahmad S, Khan T. Occupational Exposure and Respiratory Illness Symptoms Among Textile Industry Workers in a Developing Country Applied Occupational and Environmental Hygiene Vol, 2000; 15(3):313-320.

19. National Institute for Occupational Safety and Health NIOSH Pocket Guide to chemical hazards. National Institute for Occupational Safety and Health, Cincinnati, Ohio, USA, 1997;(NIOSH):97140 .

20. Jiang, et al .Occupational Diseases Prevention and Treatment Centre, Bai Yun Mountain, Guangzhou, China. Occupational and Environmental Medicine, Vol 52: 268-272.

21. National Institute for Occupational safety and Health Criteria for a recommended standard: Occupational exposure to cotton dust Washington D.C; HEW (NIOSH), 1975;75-118.

22. Beverly S, Susanne V. Air sampling instruments for evaluation of atmospheric contaminants. $8^{\text {th }}$ edition. ACGIH, Cincinnati, Ohio, 1995. 